\title{
Flusser como mediador, fenomenólogo, antropófago - uma caminhada na corda-bamba epistemológica ${ }^{1}$
}

Prof. Dr. Susanne Klengel²

\section{Quo vadis, Brasil?}

Nos anos 60 do século 20 o Brasil, visto desde a Alemanha, era um país distante e exótico. Mas no mundo da época da guerra fria, o grande país sul-americano, sua história e cotidiano conhecidos por poucos, despertava um crescente interesse político, econômico e cultural. Basta olhar a imprensa contemporâne: "Quo vadis, Brasil?" era o título de um artigo no jornal Die Welt em 15/05/1961. Sob a ótica de observadores ocidentais foi abordada a questão se o país, políticamente agitado e dividido, iria seguir o exemplo da revolução cubana sob o governo de Jânio Quadros. Depois do golpe militar de 1964 também encontram-se numerosas matérias na imprensa. A revista semanal Das Parlament, por exemplo, publicou várias delas: "Der Riese Lateinamerikas: Zukunftsland Brasilien meistert seine Probleme" ("O gigante da América Latina: Brasil, o país do futuro, supera as suas dificuldades") era o título diplomaticamente escolhido de uma reportagem abrangente, na qual se encontravam contribuições de "amigos e inimigo políticos" do novo regime.

\footnotetext{
${ }^{1}$ Este texto foi publicado em alemão, orginalmente, sob o título 'Brasilien denken. Flusser als Vermittler, Phänomenologe, Anthopophage - eine epistemologische Gratwanderung' no volume: Klengel, Susanne/Siever, Holger (Hg.). Das Dritte Ufer. Vilém Flusser und Brasilien. Ikontexte - Migration - Übersetzungen. Würzburg: Königshausen \& Neumann, 2009. pp. 111-130.

${ }^{2}$ Professora Catedrática de Literaturas e Culturas Latinoamericanas na Freie Universität em Berlim.
} 
Além da política, eram também os sinais variados de uma cultura visivelmente diferente que continuava surpreendendo com a sua estética particular e sua intelectualidade. Com a Bossa Nova e a Música Popular Brasileira, o Cinema Novo de Glauber Rocha, com a sua crítica social e estética provocativa, e as impressões futurísticas da nova capital Brasília, uma paisagem cultural se tornou visível. Aas idéias de um "melting pot" especificamente brasileiro (idéia cuja gênese se encontrava em Casa Grande E Senzala, o clássico de Gilberto Freyre, que em 1965 já estava disponível em alemão), as impressões modernas transmitidas pelos romances de João Guimarães Rosa ${ }^{3}$ ou pela Poesia Concreta ${ }^{4}$ se juntavam em um novo quadro.

O interesse pelo Brasil também é mostrado nas sessões de crítica dos jornais. No ano de 1965, o livro de Gilberto Freyre, foi seguido pelo ensaio Brasilianische Intelligenz ("Inteligência brasileira") do filósofo, semiótico e poeta Max Bense. Este texto resume as observações de duas viagens ao Brasil, que Bense fez no contexto da vanguarda concretista $^{5}$. Finalmente, a partir da metade dos anos 1960 encontram-se regularmente nos principais jornais, artigos de peritos no tema Brasil, como o suíço Hugo Loetscher,

\footnotetext{
${ }^{3}$ A mais importante obra de Guimarães Rosa, o romance Grande Sertão: Veredas, foi traduzida por Curt MeyerClason para o alemão em 1964 (Rosa, 1964). Também em jornais alemães foram publicados textos do autor brasileiro como por exemplo a história "As Garças" / " Die Reiher“. Em: Die Zeit, 19.11.1965.

${ }^{4}$ Cf. o artigo "Konkrete Poesie" ("Poesia Concreta"), de Max Bense na ocasião do décimo aniversário do poeta brasileiro do grupo Noigandres (Bense 1965b).

${ }^{5}$ Cf. a resenha de Germán Kratochwil, "Zivilisation in den Tropen. Der Deutsche Bense und der Brasilianer Freyre sehen Brasilien" ("Civilização nos trópicos. O alemão Bense e o brasileiro Freyre veem o Brasil”). In: Die Zeit, 25.02.1966. Naquela época já havia uma cooperação de longa data e relações amistosas entre Max Bense e os poetas concretistas brasileiros Augusto e Haroldo de Campos. Flusser juntamente com Anatol Rosenfeld publicou no mesmo ano uma tradução de dois poemas de Haroldo de Campos em uma antologia de poesia da série Rot organizada por Bense (de Campos, 1966). Mas obviamente nunca aconteceu um intenso intercâmbio entre Flusser e Bense.
}

Brasiliana - Journal for Brazilian Studies. Vol. 2, n.1 (March 2013). ISSN 2245-4373. 
que escreveu para o Weltwoche de Zurique ${ }^{6}$, e Vilém Flusser, que trabalhou como correspondente do Brasil para o Frankfurter Allgemeine Zeitung a partir de 1966.

Depois do Ato Institucional No. 5, em dezembro de 1968, com as suas medidas repressivas, incluindo a censura, aumentaram os relatos sobre as repressões brutais contra os oponentes do regime e a população indígena. A partir de 1969, o regime brasileiro era acusado abertamente de graves violações dos direitos humanos ${ }^{7}$. Foi nesta época que o casal Flusser decidiu deixar o Brasil depois de trinta anos, em direção à Europa ${ }^{8}$.

Essa retrospectiva breve da respresentação do Brasil na imprensa alemã mostra o esforço do público de língua alemã em obter um conhecimento atual sobre um país que estava longe de se tornar alvo do turismo de massa. Tudo isto é importante para melhor entender o papel inicial de Vilém Flusser como mediador e "intérprete" entre a cultura brasileira e a cultura de língua alemã. Pois até mesmo seus trabalhos tardios aproveitam dessa posição de observandor intercultural que exercia então, e a qual tematizaria até o fim da sua vida.

No final dos anos 60, Flusser escreveu vários textos sobre o Brasil. As suas observações culminam no, até hoje, mais famoso e ao mesmo tempo mais controverso de seus textos: a análise fenomenológica "Auf der Suche nach einem neuen Menschen. Versuch über den Brasilianer". Escrito no início dos anos 70, porém publicado

\footnotetext{
${ }^{6}$ De 1965 a 1968, Loetscher, de acordo com a pesquisa de Dewulf, publicou 12 artigos exclusivos para o Weltwoche de Zurique e, entre 1970-1972, 10 artigos para o Neue Zürcher Zeitung (Dewulf 1999). As primeiras reportagens de Loetscher lidavam com a situação política no Brasil, no entanto, posteriormente passaram a tratar da cultura e da arte.

${ }^{7}$ A extensão crítica dos relatos levou o governo brasileiro a uma réplica, que foi divulgada pela embaixada brasileira com data de 05\08\1970 sobre a alegada difamação do Brasil pelo imprensa estrangeira. O documento está disponível na documentação de imprensa do Instituto Ibero-Americano em Berlim (Pasta Bra ha, Maio 1970).

${ }^{8}$ Um exemplo é a palestra "Heimat und Heimatlosigkeit" realizada em Weiler/Allgäu, em agosto de 1985 (Flusser 1999).
}

Brasiliana - Journal for Brazilian Studies. Vol. 2, n.1 (March 2013). ISSN 2245-4373. 
postumamente, o texto que existe em versões diferentes ${ }^{9}$, possui uma atração fascinante. Depois da sua publicação no ano 1994, provocou muitos comentários que mostram a dificuldade em se entender a ligação complexa de diferentes níveis de discurso, a estereotipização existente e suposta, e a dificuldade em se avaliar a crítica de Flusser como metacrítica. O texto "transtorna" várias vezes: irrita muitas vezes os seus leitores no Brasil ${ }^{10}$, enquanto que no contexto de língua alemã é lido com uma certa estupefação como uma exposição da teoria cultural. Foi neste contexto que provocou o maior número de comentários. Daí, a questão das versões diferentes do texto publicado na Alemanha e respectivamente no Brasil ser muito importante. A versão brasileira é, por engano, muitas vezes considerada a "tradução" do texto alemão. Porém, olhando mais cuidadosamente, observam-se diferenças substanciais. As reações diferentes ao texto merecem ser analisadas contrastivamente em um trabalho de comparação entre as versões. $\mathrm{O}$ artigo presente, porém, só pode indicar a problemática, apontando para diferenças nas versões em pontos importantes.

A irritação maior provoada pelo texto, e me refiro aqui à versão alemã do mesmo, consiste na sua particular ambivalência: o discurso reflete uma inerente violência simbólica, e não evita as "rupturas" na rede do discurso, que na verdade atraem a atenção do leitor. Ou dito de outra forma, parece que a "epoké" de Flusser, isto é, o seu engajamento fenomenológico na cultura brasileira, torna visível principalmente o seu

\footnotetext{
${ }^{9}$ A versão publicada carrega o título alterado para „Brasilien oder Die Suche nach dem neuen Menschen. Versuch über den Brasilianer“ (Flusser, 1994a). Veja os detalhes da história da titulação das várias versões alemãs no "Editorisches Nachwort" da obra. (Flusser, in 1994: 317-327, aqui 323). No entanto, não há menção da versão em português, que provavelmente é dado ao fato de ter sido publicada no Brasil, depois do texto alemão, pela primeira vez em 1998, por Bernardo Gustavo Krause. (Flusser 1998).

${ }^{10}$ Krause sugere em sua introdução ao texto as possíveis objeções de leitores brasileiros contra o ensaio em sua totalidade: "Não precisamos, é claro, concordar com Vilém flusser. Professores que somso, de Geografia ou de Literatura, levantaríamos com facilidade ene argumentos contra os argumentos do filósofo. Entretanto, o seu texto não se pretende 'objetivo': ele quer um diálogo, uma conversação, o que é outra coisa." (Bernardo Gustavo Krause: " Prefácio. A épokhé brasileira." In: Flusser 1998: 7-29, aqui 24).
} 
próprio lugar como lugar sintomático de um pensamento que reflete as pressões intelectuais (e, por que não, pessoais) que resultaram de uma situação-limite. Esta situação-limite por sua vez é o resultado da conscientização de uma diferença epistêmica. Esta, de acordo com Walter Mignolo, marca posições do pensamento, no qual o sistema conceitual da tradição européia é quebrado perante outras experiências não-européias ${ }^{11}$. E Vilém Flusser ocupava ambas posições, a de observador intelectual e de participante do discurso no Brasil. Esta diferença epistêmica hoje é um teorema reconhecido na história transnacional e transcultural do saber e se formou nas últimas décadas através de uma exploração sistemática da geografia assimétrica das estruturas da percepção e através de "discursos de reconhecimento". Perante este cenário, o texto de Flusser apresenta-se como exemplo impressionante para um experimento de pensar de uma posição de limite ou de intermédiário. No meu entender, só hoje pode-se avaliar o texto na sua contraditoriedade produtiva. $\mathrm{O}$ autor mesmo estava consciente da problemática do seu texto e tenta antecipar a crítica esperada:

Durch diese Doppelzüngigkeit ihrer Botschaft läuft die Arbeit Gefahr, in Brasilien als $\mathrm{zu}$ europäisch und in Europa als $\mathrm{zu}$ brasilianisch interpretiert zu werden, also in das Kreuzfeuer der brasilianischen Ablehnung des europäischen Paternalismus und der europäischen Herablassung allem Nichteuropäischen gegenüber zu geraten und darin unterzugehen. ${ }^{12}$

\footnotetext{
${ }^{11}$ „By 'border thinking' I mean the moments in which the imaginary of the modern world system cracks. 'Border thinking' is still within the imaginary of the modern world system, but repressed by the dominance of hermeneutics and epistemology as keywords controlling the conceptualization of knowledge“ (Mignolo 2000: 23).

${ }^{12}$ [Por causa da duplicidade da sua mensagem, o texto corre o risco de ser interpretado como europeu demais no Brasil, e de brasileiro demais na Europa, ou seja de perecer no fogo cruzado entre a rejeição brasileira do paternalismo europeu e a condescendência europeia de tudo não é europeu]. Flusser 1994a: 157 A versão brasileira desvia da alemã: „A duplicidade da mensagem presente abriga perigo: ser inaceitável para o brasileiro por
} 
Para melhor captar a ambivalência profunda do texto e a interação surpreendente das diferentes representações e idéias do Brasil, é preciso mais uma contextualização histórica e cultural que esclareça a relação de Flusser com a scientific community do Brasil, da qual era partícipe e observador ao mesmo tempo. Alguns textos que examinaremos em mais detalhe a seguir oferecem este esclarecimento. Flusser pronuncia-se neles acerca da vida intelectual e da produção filosófica no Brasil entre 1967 e 1971. É verdade que se observam certas mudanças nos argumentos ao longo dos anos, mas a questão de todos estes textos é do dilema entre a universalidade e a especifidade cultural na filosofia. Em outras palavras: o filosofar no "centro" ou na "periferia" é que se apresenta como o problema que Flusser tratará de maneira ambivalente em suas observações. A problemática dos lugares e do posicionamento é baseado também no fato de que esses textos estão situados num contexto receptivo transatlântico e por meio da tradução mudam-se também os destinatários, o contexto de referência e as reações, como será visto a seguir.

\section{2. (Como) Se filosofa no Brasil?}

Os artigos de Flusser "Wie philosophiert man in Brasilien? Dargestellt an drei exemplarischen Denkern” ("Como se filosófa no Brasil? Demonstração em três pensadores paradigmáticos"), publicado no Frankfurter Allgemeine Zeitung do dia 3 de janeiro de 1967 (Flusser 1994b: 229-236) e „Brasilianische Philosophie“ (“Filosofia

excessivamente européia, e para o europeu por excessivamente brasileira. E uma vantagem possível: permitir tanto ao brasileiro quanto ao europeu se ver a si próprio de fora. A vantagem, se for real, não exige comentário, já que se oferece no próprio ensaio - ou não existe. (Flusser 1998: 164). As edições posteriores diferem substancialmente em ambas línguas.

Brasiliana - Journal for Brazilian Studies. Vol. 2, n.1 (March 2013). ISSN 2245-4373. 
brasileira"), publicado no Anuário do Instituto Hans Staden de São Paulo (Flusser 1970) formam os pontos centrais deste texto. A Revista Brasileira de Filosofia, a partir de uma tradução do primeiro dos textos para o português, trouxe uma recepção muito crítica do mesmo e esta crítica obviamente influenciou consideravelmente a argumentação de Flusser no segundo texto. A seguir, focalizaremos esta disputa de fundo, pois é significativa para uma avaliação mais exata do estudo fenomenológico Auf der Suche nach einem neuen Menschen. Versuch über den Brasilianer.

No artigo mencionado, de janeiro de 1967, Flusser insiste numa diferença fundamental entre uma filosofia "real", independente de lugar e tempo, e uma filosofia que está marcada por circunstâncias (como o lugar, as instituições ou motivos específicos). À questão se no pensamento filosófico no Brasil realmente existem tentativas "disciplinadas" de "dem menschlichen Dasein in Brasilien Sinn und damit Würde zu geben“ ("dar sentido e dignidade à existência humana”) (Flusser 1994b: 231), o qual seria o dever da filosofia "real", Flusser responde, em grande parte, negativamente: ao contrário, ele aponta que predominaria um "ecleticismo selvagem" e que a expressão filosófica seria substituida por uma "literatura de romance" e pela "crítica literária" (ibid.: 230). A hierarquia acentuada de Flusser, que parte de uma distinção rigorosa entre discurso filosófico e discurso literário (em sentido lato), não somente parece pejorativa ${ }^{13}$, mas também contesta o pensamento e escritura filosóficoensaística, tão pronunciados na tradição intelectual latino-americana. Isso é surpreendente considerando que este é o caráter de muitos dos textos do próprio Flusser! Ao mesmo tempo, Flusser assegura que no Brasil, de fato, há exemplos para uma filosofia realmente brasileira e universal: Menciona três pensadores que seriam

\footnotetext{
${ }^{13}$ Cf. a este respeito, por exemplo, o pensamento e comentários de David Jackson sobre o papel da crítica literária como parte integrante da história e crítica intelectual brasileira desde o século XIX (Jackson, 1996).
}

Brasiliana - Journal for Brazilian Studies. Vol. 2, n.1 (March 2013). ISSN 2245-4373. 
filósofos "no pleno sentido da palavra": Vicente Ferreira da Silva, próximo à filosofia existencial de Heidegger, como pensador de uma estética específicamente brasileira; o matemático e filósofo da economia Leônidas Hegenberg como representante da epistemologia brasileira; e o filósofo do direito e da cultura Miguel Reale, fundador e presidente do Instituto Brasileiro de Filosofia e catedrático da Universidade de São Paulo, como representante de uma ética brasileira. A filosofia daqueles três, segundo Flusser, possui uma "validade universal"14.

O artigo de Flusser foi traduzido sem demora para o português por Ireneu Sprenger, sócio, como Flusser, do Instituto Brasileiro de Filosofia, e foi publicado dois meses depois com o título modificado de "Há Filosofia no Brasil? Demonstração em três pensadores expressivos" (Flusser 1967). Suspeita-se que esta mudança provocadora de ênfase exigiria uma resposta. Já dois números depois saiu uma crítica muito cortês, porém muito determinada, à qual Flusser responderia no mesmo lugar („Há Filosofía no Brasil? Diálogo de Nelson Saldanha e Vilém Flusser.“ 1967) ${ }^{15}$. O filósofo Nelson Saldanha, do Recife, próximo ao culturalismo, acusa Flusser de uma simplificação inválida, quando define os três filósofos paulistanos como representantes únicos de uma filosofia brasileira reduzida à estética, epistemologia e ética ${ }^{16}$. A crítica, além da acusação de um reducionismo incabível, torna visível, antes de tudo, a discrepância

\footnotetext{
${ }^{14}$ Flusser, 1994b: 236. Sobre o contexto científico destes filósofos da história da filosofia brasileira ver Paim ${ }^{3}$ 1984, especialmente o capítulo "Fenomenologia e existencialismo" (ibidem: 552-563) e "A Escola Culturalista" (ibid: 578604).

${ }^{15}$ A resposta crítica a Flusser era óbvia já que o Instituto Brasileiro de Filosofia tratou em seu boletim de maneira particularmente forte da história e institucionalização da filosofia no Brasil.

16 "Há Filosofia no Brasil? Diálogo de Nelson Saldanha e Vilém Flusser" 1967: 300-302. Embora Saldanha não se refira explicitamente em seu comentário à Escola do Recife, que a partir do Século 19 teve como um de seus principais representantes Tobias Barreto que impulsionava uma renovação filosófica na vida intelectual brasileira, este saber implícito é importante para se entender o espírito brasileiro e a filosofia da história, tema sobre o qual Saldanha apresentou um estudo monográfico em 1976, muito relacionado ao culturalismo da tradição da Escola do Recife. (Saldanha, 1985).
}

Brasiliana - Journal for Brazilian Studies. Vol. 2, n.1 (March 2013). ISSN 2245-4373. 
problemática entre a metrópole São Paulo e o resto do Brasil, chamada implicitamente de 'província filosófica' por Flusser. Assim chegamos à problemática da localização central ou periférica dos pensadores brasileiros. Sem dúvida, esta questão também foi abordada na publicação original do artigo de Flusser no Frankfurter Allgemeine Zeitung só que no sentido inverso. Porque, visto a partir de um contexto alemão e europeu, ainda a metrópole São Paulo parece uma localidade 'ex-cêntrica' para o pensamento filsosófico. Porém, o problema das assimetrias na percepção e no reconhecimento da produção intelectual (será refletido mais tarde, nos estudos pós-coloniais, através do conceito de 'location of culture' de Homi Bhabhas), para Flusser ainda não é um problema epistemológico (ainda que ele mesmo está continuadamente confrontado com o fato de ser um intelectual no Brasil 'periférico'). Na sua resposta a Saldanha, Flusser explica então que, na área da filosofia, considerar a geografia seria um verdadeiro pecado, que ele mesmo (Flusser) também teria cometido (porque, com vista aos seus leitores alemães, haivia utilizado o termo "filosofia brasileira"). Sua preocupação fora, porém, simplesmente o esclarecimento da pergunta, se no Brasil existiam "filósofos verdadeiros" ou só "discursos sobre a filosofia". Nem "brasilidade" nem “pernambucanidade” estariam em discussão neste caso („Há Filosofia no Brasil? Diálogo..." 1967: 302-304). Perante esta disputa não parece coincidência, que nesta edição da Revista reimprimiram um documento do ano 1907: a coleção bibliográfica de dados colecionados por Prado Sampaio com o título “Os nossos filósofos" que disponibiliza uma visão geral sobre os representantes da história das idéias do século 19, com ênfase à importância da Escola do Recife para a vida intelectual brasileira (Sampaio 1967 [1907]).

Depois desta troca de opiniões, não saem mais publicações de Flusser na Revista Brasileira de Filosofia até 1969.

Brasiliana - Journal for Brazilian Studies. Vol. 2, n.1 (March 2013). ISSN 2245-4373. 
Entretanto, devido ao seu artigo no Frankfurter Allgemeine Zeitung, a editora Rombach \& Co. consulta Vilém Flusser sobre a possibilidade de este publicar uma antologia comentada da vida intelectual brasileira contemporânea, no entanto esse projeto nunca foi realizado ${ }^{17}$. Em 1970 saiu o segundo artigo de Flusser sobre a "Filosofia Brasileira" (!) no Jahrbuch do Instituto Hans Staden em São Paulo, novamente em alemão. Trata-se de uma versão modificada e aumentada do artigo de 1967, no qual volta a listar os três filósofos já mencionados como representantes centrais da filosofia brasileira contemporânea. Contudo, agora admite uma certa distorção, por que sua vista estaria fixada em São Paulo. Ao mesmo tempo, suplementa um fato importante ao conteúdo ao qual voltaremos mais tarde neste texto.

Finalmente, Flusser entrega seu manuscrito de 130 páginas do Auf der Suche nach einem neuen Menschen. Versuch über den Brasilianer a Gerd-Klaus Kaltenbrunner, revisor da editora Rombach. Mas a editora rejeita o trabalho. Aparentemente, Kaltenbrunner não esperava esta maneira de debruçar-se sobre o pensamento e os fenômenos da cultura brasileira. A versão alemã foi publicada postumamente em 1994, a versão brasileira em 1998.

O artigo „Wie philosophiert man in Brasilien?" ("Como se filosofa no Brasil?”) (Flusser 1994b) está relacionado com aquela coleção de artigos sobre a cultura brasileira mencionada anteriormente, que Flusser começou a escrever a partir de 1966, na maioria dos casos para o Frankfurter Allgemeine Zeitung. Refletem o interesse alemão no Brasil, que já foi delineado. Tratam da 'nova cultura' do Brasil, dos trópicos e seu clima, de comparações de culturas que Flusser fez depois de uma viagem ao 'mundo branco' (europeu), tratam do Brasil como um laboratório para a renovação da língua

\footnotetext{
${ }^{17}$ Cf. „Editorisches Nachwort“. In: Flusser 1994: 323.
}

Brasiliana - Journal for Brazilian Studies. Vol. 2, n.1 (March 2013). ISSN 2245-4373. 
portuguesa, etc ${ }^{18}$. Hoje, o leitor com conhecimentos das teorias culturais sente uma certa distância destes artigos. Isto é devido ao fato de que algumas declarações parecem historicamente obsoletas, por exemplo, o discurso enfático de uma nova cultura brasileira e a utopia de um futuro melhor ligado a ela (e também o discurso do seu fracasso). Por outro lado, encontram-se hoje desdobradas e desevolvidas em contextos de teorias diferentes muitas das observações de Flusser: p. ex., suas teses da mistura de culturas hoje estão suspensas em um discurso diferenciado sobre a hibridação cultural, mas cuja compreensão dinâmica da cultura, no entanto, ainda era inconcebível para Flusser.

Junto com os textos sobre a filosofia, estes artigos do Frankfurter Allgemeine Zeitung formam o verdadeiro núcleo do futuro ensaio de Flusser sobre o Brasil. No entanto, nele o foco mudou fundamentalmente. O que aconteceu? Por que este texto não pode ser lido com a mesma calma da distância histórica que os artigos culturais? Por que o desassossego e a irritação?

\section{A fenomenologia do Brasil de Flusser: olhares, imagens e interpretações}

Flusser vê seu ensaio como uma fenomenologia do "Brasil que ele viveu". Não quer se basear explicitamente em um saber já existente, assim raramente se refere a obras brasileiras ou não-brasileiras:

[...] alles etwa vorhandene Wissen in diesen Gebieten [d. i. Soziologie, Ökonomie, Ethnologie usw. SK] [wird] bewußt eingeklammert, um ein

\footnotetext{
${ }^{18}$ Estes artigos de jornais foram publicados em Flusser, 1994.
} 
erlebtes Brasilien, eben als die Lebenswelt, zu Wort kommen zu lassen. ${ }^{19}$ (Flusser 1994a: 15-16)

Flusser 'põe entre parêntesis' (no sentido de 'excluir'), mantém distância e ocupa a sua posição fora dos contextos, debates e conhecimentos científicos contemporâneos - e assim deliberadamente fora da discussão sobre a identidade brasileira e fora do discurso acadêmico sobre a 'brasilidade'. Desta forma, tenta ocultar a ampla discussão científica e pública sobre o 'nation building' cultural da modernidade nacional no século 20. Esta discussão era conduzida, tanto no Brasil, como em outros países latinoamericanos, sobretudo no nível da reflexão cultural ${ }^{20}$.

Comparado aos seus artigos anteriores sobre o Brasil, a novidade do seu ensaio não é apenas o aumento na complexidade de seus pensamentos, mas sim, acima de tudo, a encenação de um caleidoscópio de posições e perspectivas: Flusser continua cruzando duas perspectivas opostas e tenta diagnosticá-las, observando tudo de uma terceira posição, a do 'imigrante intelectual'.

Ele então constata um olhar duplo sobre o Brasil, um de fora e um brasileiro. Mas não explicará a diferença entre os dois imaginários do Brasil por meio da idéia vaga da 'alteridade' do Brasil, como ainda fez nos artigos no Frankfurter Allgemeine Zeitung. Mas

${ }^{19}$ [(...) todo conhecimento já existente nestas áreas [i. e. sociologia, economia, etnologia etc. SK] está posto entre parêntesis conscientemente, para deixar falar um Brasil vívido, precisamente como o ambiente de vida."].

${ }^{20}$ Essa discussão sobre a "Formação do Brasil é baseada em um corpus abrangente de textos do século 20 especialmente Os Sertões (1902) de Euclides da Cunha, os modernistas dos anos 20, Retrato do Brasil (1928) de Paulo Prado, Casa Grande \& Senzala (1933) de Gilberto Freyre, Raízes do Brasil (1936) de Sérgio Buarque de Holanda, Formação do Brasil Contemporâneo (1942) de Caio Prado Júnior, Formação da literatura brasileira (1959) de Antonio Candido e Formação Econômica do Brasil (1959) de Celso Furtado (cf. por exemplo, a coleção de ensaios Dantas Mota ${ }^{32001) . ~ F l u s s e r ~ c o m ~ c e r t e z a ~ c o n h e c i a ~ e s t a s ~ o b r a s ~ e ~ d i s c u s s o ̃ e s, ~ m a s ~ e l e ~ m e n c i o n a ~}$ explicitamente apenas Os Sertões de Euclides da Cunha, e a réplica magistral de João Guimarães Rosa em seu romance Grande Sertão: Veredas, e o Modernismo de 1920. Para esse fluxo culturalista na filosofia brasileira que remonta ao Século 19 (Escola do Recife), Flusser mostra uma relação ambivalente, como prova a já mencionada resposta a Saldanha.

Brasiliana - Journal for Brazilian Studies. Vol. 2, n.1 (March 2013). ISSN 2245-4373. 
bem vê um contraste entre o olhar 'histórico' dos países assim chamados 'históricos' e o olhar 'não-histórico' dos brasileiros. Assim, o ensaio está marcado pela mudança de ênfase que focalizará agora a idéia da historicidade e da não-historicidade e que será apresentada em forma de dicotomia ${ }^{21}$. História e tradição, defasagem, historização e imitação como problema, mas também as oportunidades de uma não-historicidade existencial serão então os temas da análise sobre o Brasil proposta por Flusser ${ }^{22}$.

\section{O poder da história e seus conceitos}

A primeira perspectiva corresponde ao lugar do mundo ocidental, o "mundo branco" (como escreveu Flusser em 196723). A segunda corresponde ao Brasil e não reflete, segundo Flusser, a perspectiva dos 'países históricos' pois o Brasil não participa da história dos mesmos. Mas Flusser trata ambas as perspectivas, histórica e não-histórica, desde a discreta distância da sua 'terceira posição' de imigrante entre os dois mundos. Mas aqui se abre um problema epistemológico: Flusser não consegue definir o ‘Brasil não-histórico' desde sua terceira posição (de observador), porque para isto, ele necessita de um conceito de história, proveniente da primeira das posições descritas.

\footnotetext{
${ }^{21}$ No ensaio de Flusser, as observações sobre a não-historicidade do Brasil são numerosas. Ele fala de "aroma inebriante" do anti-historicismo (Flusser, 1994a: 37), de uma "frouxidão" que vem da história da América Latina (ibid.: 41), da "natureza extra-histórica" do brasileiro e sua "loucura historicista "' (ibid.: 70 ). A não historicidade é expressa por um lado como uma imitação defasada, sem criatividade e alienada, e por outro, como um alivio, como contenedora de todas as possibilidades de novos projetos para um futuro aberto.

${ }^{22}$ É interessante neste contexto que também Max Bense contate que há no Brasil uma "consciência não-histórica, que não olha para trás, mas mantém-se prospectiva" (ver Bense 1965a: 12). Bense, no entanto, e diferentemente de Flusser, elabora um discurso intelectual sobre literatura, arte e arquitetura e ainda que fascinado por seu potencial inovador, não tentou criar nenhuma interpretação geral do Brasil. Em um de seus aforismos expressa: "Das Schöpferische ist nie geschichtlich, immer nur aktuell"["O criativo nunca é historicamente, mas sempre atual”] (ibid.: 59).

${ }^{23}$ Vilém Flusser: "Nach einer Reise in die weiße Welt. Ein Brasilianer kehrt zurück". ("Depois de uma viagem ao mundo branco. A volta ao Brasil"). In: Flusser 1994: 201-205.
}

Brasiliana - Journal for Brazilian Studies. Vol. 2, n.1 (March 2013). ISSN 2245-4373. 
Consequentemente, sua posição depende dos conceitos dos países ‘históricos'. E mesmo concentrando-se nas formas de vida e existências do lado brasileiro, continua definindo os fenômenos, problemas, contradições por meio de critérios e conceitos que tira da 'posição histórica'.

De fato, observando as concepções de história, desenvolvimento e progresso, divulgados nos anos 60 e 70, no caso de Flusser revela-se rapidamente uma argumentação influenciada pelos seguinte conceitos contemporâneos: o desenvolvimento tecnocrático-positivista (p. ex. no regime militar no Brasil), o pensamento progressista da burguesia liberal (na tradição do historicismo clássico), a história progressista marxista e a teoria da dependência, que tem origem na América Latina e pensa o progresso sócio-econômico dos países 'em desenvolvimento' como algo sistêmico na estrutura econômica e política entre o Primeiro e o Terceiro Mundo.

Apesar de grandes diferenças, estes conceitos têm em comum uma idéia parecida de um desenrolar progressivo da história. Também o pensamento de Flusser tem origem nesse ambiente do conceito ainda hegeliano de história. Por outro lado, outros conceitos de história, como a géohistoire ou a longue durée, ou seja o modelo mais estrutural das diferentes velocidades históricas de Fernand Braudel, passsam longe do pensamento flusseriano. (mesmo que o conceito de história de Braudel, tenha influenciado essencialmente o Brasil nos anos de 193024.)

Flusser também deixa de fora o que os historiadores brasileiros da época estavam lamentando como uma crise em sua disciplina. O historiador José Honório Rodrigues esboçou a situação de crise da historiografia no Brasil na metade dos anos 60 durante um colóquio com acadêmicos das humanidades e da sociologia. Ante tudo, se queixou

\footnotetext{
${ }^{24}$ Como Flusser, também Braudel era fascinado pela geografia aparentemente estagnada do sertão brasileiro, o que influenciou em seu pensamento histórico (cf. Klengel 1996).
}

Brasiliana - Journal for Brazilian Studies. Vol. 2, n.1 (March 2013). ISSN 2245-4373. 
de uma historiografia antiquada e revisionista, que estava fixada no passado num sentido museal, e que não oferecia nenhuma referência para a compreensão do presente:

Não se tratava propriamente de uma crise momentânea, mas da permanência de um pensamento histórico especialmente antiquário e revisionista. [...] O mal consiste essencialmente no total desinterêsse pela história contemporânea e especialmente na falta de resposta aos apelos e complexidades presentes. (Rodrigues o.J.: 79)

Esta falta de interesse deveria ser combatida por meio de uma profissionalização e modernização crítica da disciplina. Neste contexto, Rodrigues remete a conceitos mais novos, como p. ex. a historiografia francesa ou a historiografia neomarxista. Não obstante, não vê neles a solução da crise. Flusser, no entanto, cujos pensamentos são, ao fim e ao cabo, também expressões desta crise, interpreta o espírito "antiquário" - o qual, segundo ele, se mostra francamente como "loucura historicista" (Flusser 1994a: 70) - no mesmo sentido que Nietzsche o entendia: um passo para a perda da liberdade. A interpretação flusserianaque assume que "o brasileiro" seria um "ser extra-histórico" e por isso teria uma "liberdade fundamental" (ibid.), parece surpreendentemente essencialista, ante as exposições de Rodrigues. Flusser toma a crise na conciência histórica anunciada por historiadores e a falta de modernidade nos métodos historiográficos como ponto de partida para uma construção do não-histórico como 'caraterística'. De fato, um resultado bastante estranho do 'pôr entre parêntesis' flusseriano que revela-se, na verdade, como uma exclusão de debates atuais.

No entanto, na perspectiva de hoje, a problemática conceptual de Flusser pode ser articulada de uma maneira diferente: Apenas poucos anos antes do 'linguistic turn' nas 
ciências sociais e humanas, respectivamente antes da destronização das 'grandes narrativas' pela filosofia pós-moderna, Flusser não tem ainda nenhuma dúvida sobre o 'grand récit' da historiografia ocidental - embora constate um choque na convicção ocidental do progresso. Para Flusser, a possibilidade de uma divisão da história em numerosas histórias distintas ainda é inconcebível. Assim, não enxerga a modernidade na sua pluralidade, respectivamente na sua fragmentação que simplesmente não corresponde com o padrão da modernização uniforme (e ocidental). Esta é a base que determina a dicotomia 'história vs. não-história' no imaginário de Flusser sobre o Brasil contemporâneo.

Com base nessa dicotomia Flusser criou as suas hipóteses, hoje bastante estranhas, p. ex. sobre a 'Bodenlosigkeit des Brasilianers' (literalmente a falta de chão do Brasileiro, entendida no sentido de uma falta de base histórica como locus cultural) ou sobre os fenômenos da simultâneidade do des-simultâneo histórico, que Flusser chamará de 'defasagem'. Isto se mostrava especialmente claro no comportamento imitativo da burguesia brasileira, que Flusser rejeita profundamente, como rejeita tudo o que é 'pose' ${ }^{25}$. São da mesma forma decididamente baseadas nesta dicotomia suas observações acerca da 'alienação' fundamental dos brasileiros e também as suas visões do 'homem novo' ou 'ser humano' no Brasil e da possível gênese de uma "terceira cultura" exemplar.

\section{Mudança de perspectiva - sobre o jogo das interpretações e significados}

\footnotetext{
${ }^{25}$ Por trás da idéia de 'defasagem' se esconde um conceito de modernização, que acredita que esta ocorre de acordo com um padrão europeu-ocidental específico. E também de uma extratemporalidade histórica, de um atraso histórico e daí finalmente, uma carga de imitação e de ecletismo que se pode encontrar claramente formulado em Flusser (ver Flusser, 1994a: 80-81). Esta visão também explica a insistência em Flusser no "avanço criativo" ou de uma "mudança radical" como uma saída possível dessa situação (ibid.).
} 
Porém, essa interpretação desde a perspectiva dos 'países históricos' (que, finalmente, determinam as exposições de Flusser no que diz respeito ao seu conteúdo conceitual), será minada por ele mesmo, com a ajuda de uma mudança de ponto de vista para a perspectiva brasileira. Neste momento, Flusser denuncia os termos e atribuições que havia usado recentemente: Repetidamente aponta que os termos, teorias e denominações de épocas européias estão inadequados à realidade concreta do Brasil. Aponta que teriam um efeito de distorção se fossem usados como adequados para a realidade brasileira.

O conceito europeu de época e estilo 'barroco', por exemplo, significava algo diferente no Brasil e na Europa. O barroco brasileiro seria uma mistura do estilo europeu com influências africanas e indígenas, do qual surgiu uma síntese muito extraordinária, e assim algo completamente novo - apesar da suposta semelhança com o barroco europeu. ${ }^{26}$

Flusser também examina meticulosamente o conceito hegeliano-marxista da 'alienação' no contexto basileiro. Constata razões diferentes para a alienação, que nos 'países históricos' tinham sua base no materialismo e no 'encarceramento' mental do homem. No Brasil não-histórico, no entanto, a causa era uma improcedência concreta, uma suspensão permanente, uma flutuação no vazio, um 'ainda-não' constante, que alguma vez até poderia tornar-se numa nova individualidade e originalidade (ver nota 25). Por outro lado, porém - e isso é o giro mais importante do conceito - o que parece 'alienado' desde a perspectiva histórica (como por exemplo carnaval e futebol, que frequentemente são interpretados como evasão de uma realidade insuportável), pode ser a expressão de uma nova forma de vida. Por exemplo, Flusser encontra no Brasil o

\footnotetext{
${ }^{26}$ Ibid: 72. Para uma discussão abrangente sobre a história e a importância do barroco no Brasil e na América Latina, ver o volume organizado por Schumm 1998
}

Brasiliana - Journal for Brazilian Studies. Vol. 2, n.1 (March 2013). ISSN 2245-4373. 
tipo do 'homo ludens', que "in einer anderen Wirklichkeit lebt und ein anderes religiöses Erleben hat" ("mora numa realidade diferente e tem uma experiência distinta de religião") (Flusser 1994a: 99). Com ele, descobre uma atitude diferente, brincalhão para a vida, cuja discussão com o conceito histórico da alienação seria absolutamente absurdo.

Flusser re-avalia conceitos - entre eles o conceito de 'miséria', seu conteúdo e a maneira da sociedade de lidar com ele. No Brasil, segundo Flusser. miséria existencial não era diagnosticada como carência, como nos países históricos. Lá, era resolvida com serenidade teológica e assim movia-se a roda fatal do progresso. Medo e ansiedade em relação ao futuro, o que exigiria uma solução da miséria, no Brasil raramente resultavam num sentido de verdadeira responsabilidade, mas frequentemente num amor prático e não-romântico ao próximo e num jogo criativo, do qual surgiria, então, a solução para a miséria (ver ibid.: 119, 122).

Uma vez mais, Flusser tenta demostrar que os conceitos históricos tradicionais no Brasil não funcionam. Assim, só no Brasil se entenderia que 'cultura' na verdade se encontra nos gestos diários do corpo, na música, no ritmo da bossa nova. Porém o que no Brasil estava sendo chamado de 'cultura', era na maioria dos casos uma pose, uma retórica adotada da Europa. Por isso, Flusser não está interessado nas regras da língua portuguesa, mas sim nas quebras dessas regras na variante brasileira. Para ele, esta quebra das normas sugere uma criatividade extraordinária, que no português europeu nem seria pensável ${ }^{27}$. Encontra provas diversas na literatura brasileira: em Machado de Assis, maior autor realista do século 19, como Flusser escreve, no movimento

\footnotetext{
${ }^{27}$ Cf. o capítulo "Sprache” (Flusser, 1994a: 145-156), a versão brasileira (em Flusser 1998: 153-161), difere no entanto consideravelmente da alemã.
}

Brasiliana - Journal for Brazilian Studies. Vol. 2, n.1 (March 2013). ISSN 2245-4373. 
vanguardista da antropofagia dos anos 1920, na poesia concreta dos anos 1950 e nos textos de João Guimarães Rosa, renovador da linguagem literária ${ }^{28}$.

No seu ensaio, Flusser se dedica de certa forma a uma 'desconstrução' do vocabulário e do discurso histórico, tentando descubrir os limites dos termos (europeus) e dos seus significados no contexto cultural brasileiro. Mas o ultrapassar dos conceitos com os próprio conceitos é tarefa difícil. Flusser está consciente disso e também de como ele mesmo falha na tarefa, como mostram as reações ao seu texto sobre o Brasil, ambilvalentes até hoje. Seus objetivos, mediação intercultural e autorreflexão, continuam produzindo mal-entendidos.

Daí que Flusser convida a uma (meta)crítica no seu próprio texto e ao mesmo tempo indica a uma aporia iminente:

Eine echte brasilianische Kulturkritik darf sich nicht auf importierte Kategorien beschränken [...], sondern muß versuchen, dem Phänomen selbst seine Kategorien abzulauschen. [...] Inwieweit diese Aufgabe überhaupt lösbar ist und sich importierte Kategorien in Form von Vorurteilen immer einschleichen, könnte zum Beispiel eine Kritik der vorliegenden Kritik [gemeint ist Flussers eigener Essay, S. Klengel] untersuchen. Eine derartige Metakritik zu provozieren, ist eine der Absichten dieser Arbeit ${ }^{29}$. ( Flusser 1994a: 127)

\footnotetext{
${ }^{28}$ É surpreendente que, aparentemente, Flusser não mencione, Clarice Lispector, que junto com Guimarães Rosa, foi uma grande renovadora da literatura brasileira. Max Bense, pelo contrário. cita Lispector como uma interlocutra importante e se refere à obra dela em seu livro. (ver Bense 1965a: 30-32, 58).

${ }^{29}$ [Uma verdadeira crítica da cultura brasileira não deve se limitar à categorias importadas [...], tem que tentar de escutar às categorias do próprio fenômeno. [...] Até que ponto este problema pode ser resolvido e até que ponto categorias importadas sempre se infiltram em forma de preconceitos poderia ser analisadas em uma crítica da crítica presente [i. e. o ensaio do prórpio Flusser]. Provocar uma meta-crítica dessas é um dos objetivos deste trabalho.] (Flusser 1994a: 127). A versão brasileira difere significativamente da versão alemã. Sobre a passagem
} 


\section{De fenomenologista a antropófago? Vilém Flusser e Oswald de Andradre - um jogo criador}

Uma desconcertante posta em perspectiva marca o texto de Flusser, com seus ângulos e posições de observador múltiplo. O discurso, que muitas vezes soa apodíctico contém na sua natureza a tentativa da própria escavação, ou 'desconstrução'. Mas esta realmente não é atingida. A razão é um essencialismo, do qual a fenomenologia de Flusser muitas vezes não consegue fugir. Embora Flusser consiga refletir e pôr entre parênteses a gaiola dos conceitos históricos que há muito tempo marcaram o discurso entre a Europa e o Brasil, sobretudo 'sobre' o Brasil, ele mesmo não consegue sair da gaiola dos conceitos/significados. Ele fica preso às dicotomias porque, muito além do discurso, Flusser busca uma resposta à pergunta sobre o futuro do homem, que ele vê ameaçado pela ideologia do progresso do mundo histórico.

Como esta busca existencial e existencialista está ligada ao contexto de textos e leituras brasileiros, explicamos a seguir.

Seguindo Flusser, para resolver a miséria humana realmente existente, não é necessário uma "Überholung des Elends durch Fortschritt" ("ultrapassar a miséria pelo progresso"), entendida como um telos histórico, perseguido teimosamente e com serenidade (Flusser 1994: 122). Em vez disso, ele esboça uma 'forma brasileira' da preocupação com o futuro, que se opõe ao fervor teleológico e o faz com o retorno a dimensão existencial do 'jogo': "Laßt uns also unsere Sorge in schöpferisches Spiel

correspondente lê-se:,[...] uma crítica consciente tem tarefa imensa no Brasil, a saber elaborar suas próprias categorias [...] As categorias propostas [Flusser se refere a seu próprio texto. S. Klengel] não serão impostas aos fenômenos que revelem as suas próprias categorias (se tal afirmativa é ou não é verdadeira será tarefa de crítica posterior constatar, e a esperança do presente capítulo é provocar tal indispensável metacrítica)" (Flusser 1998: 133).

Brasiliana - Journal for Brazilian Studies. Vol. 2, n.1 (March 2013). ISSN 2245-4373. 
verwandeln." ("transformemos as nossas preocupações num jogo criativo.") (ibid.: 123) O jogo não só significa a preservação de relações humanas, mas sim abre caminho para lidar com o absurdo da existência humana. Pois o conhecimento novo (e velhíssimo ao mesmo tempo) que tudo é apenas um jogo (inlcusive o amor e a morte) também oferece a possibilidade de reorganizar tudo e, assim, "dem Sinnlosen Sinn zu geben" ("dar sentido ao que estava sem") (ibid. 122, ver tb. 163-166). Daí, o convite ao jogo, para Flusser, também é o convite para empenhar-se contra a miséria e para um futuro melhor. A abordagem brasileira de históra se encaixa neste conceito: Se tudo é jogo, a história também faz parte dele. Sabendo disso, entende-se melhor a frase de Flusser "dass ein ungeschichtliches Denken fähig ist, sich die Geschichte einzuverleiben" ("que um pensamento não-histórico é capaz de incorporar a história") (ibid.:154).

Essa idéia do futuro da humanidade, da incorporação da história pela não-história e do advento da cultura brasileira como alternativa alude a um topo muito bem conhecido no debate sobre a identidade brasileira do século 20 (que Flusser cita brevemente no seu ensai $\left.^{30}\right)$. Trata-se da linha mais famosa do Manifesto Antropófago de Oswald de Andrade do ano 1928: "Tupi or not Tupi - that is the question". Flusser cita este jogo de linguagem irônico e também muito sério sobre o poder da tradição (européia), no qual Oswald de Andrade 'canibaliza' parodicamente a Shakespeare através de imagens indígenas e fantasias canibalistas, que apontam à época do encontro europeu com os povos tupi. O verso contém no núcleo o programa da antropofagia cultural, que, como estratégia subversiva e lúdica da absorção e hibridação, marca até hoje as discussões da teoria da cultura na América Latina ${ }^{31}$.

\footnotetext{
${ }^{30}$ Flusser, 1994a: 153 . Surpeendentemente a versão brasileira carece exatamente desta exata citação modernista.

${ }^{31} \mathrm{Cf}$, por exemplo o ensaio de Haroldo de Campos, que assumiu a Antropofagia no contexto do pensamento pósestruturalista. O ensaio é um dos textos básicos das atuais das teorias culturais latinoamericanas. (cf. de Campos, 1990).
}

Brasiliana - Journal for Brazilian Studies. Vol. 2, n.1 (March 2013). ISSN 2245-4373. 
Efetivamente, parece que o programa de reavaliação e reinterpretação que Flusser descreve no seu ensaio sobre o Brasil está ligado ao conceito de 'canibalismo cultural', que recebeu de novo muita atenção nos anos 60, através do movimento cultural tropicalista. Flusser não somente menciona o potente movimento de vanguarda no âmbito das suas conclusões, mas também o identifica como um dos fenômenos culturais 'verdadeiros', semelhante à literatura de João Guimarães Rosa ou a Poesia Concreta. Estes fenômenos teriam 'quebrado' a natureza imitativa da cultura brasileira alienada. Além disso, em seu ensaio Flusser adota uma possibilidade do metabolismo simbólico dos antropófagos culturais: a possibilidade de virar contra si mesmo o discurso da história e da tradição, num ato de incorporação simbólica. Com certeza, expressar e conceptualizar esta figura num texto filosófico é mais difícil que num manifesto vanguardista, que finalmente só remete a si mesmo. É por isso que a imagem da 'incorporação' apenas aparece discretamente nos textos do filósofo. Mas, por fim, sua idéia central do 'Brasil não-histórico' culmina na observação, que no Brasil, aparentemente, um "ungeschichtliches Denken fähig ist, sich die Geschichte einzuverleiben" 32 " ("o pensar não-histórico é capaz de incorporar a história"). Esta 'incorporação canibalista' consiste no tratamento sem respeito, eclético e brincalhão com modelos e padrões. Nesse sentido, a 'desconstrução' dos conceitos históricos de Flusser pode ser vista como um ato metabólico, marcado pela esperança especificamente antropófaga de aumento de sentido e significado (no sentido de enriquecimento linguístico-cultural).

Flusser recorre ao ideário brasileiro também no artigo "Brasilianische Philosophie" ("Filosofia Brasileira") (Flusser 1970), que esclarece seu pensamento. Neste artigo, dirige

\footnotetext{
${ }^{32}$ Flusser, 1994a: 154. Na versão brasileira do texto está faltando, no entanto esta metáfora no momento apropriado e aparece formulada em outro contexto completamente diferente: "E no Brasil trata-se da tentativa de descobrir a própria identidade, que é identidade não-histórica, portanto não-linear e nã-discursiva.”(Flusser 1998:160)
}

Brasiliana - Journal for Brazilian Studies. Vol. 2, n.1 (March 2013). ISSN 2245-4373. 
sua atenção não apenas aos filósofos Vicente Ferreira da Silva, Leônidas Hegenberg und Miguel Reale, mas também a Oswald de Andrade. Aqui, pela primeira vez, Flusser aprecia o escritor modernista como filósofo. O vê inclusive como 'fundador' da filosofia brasileira, e considera que sua importância para o pensamento brasileiro ainda não fora de todo reconhecida (ibid.: 134-135). No seu artigo se refere principalmente à obra tardia oswaldiana, especialmente ao ensaio filosófico "A crise da filosofia messiânica"33, no qual Flusser descobre pensamentos que pouco tempo depois usará em seu próprio ensaio sobre o Brasil como argumento central. Trata-se da idéia do homem como um ser jogador no sentido existencial, e daí depreende uma teoria do jogo que vai além de Huinziga, posto que entende o homem como ser artista, capaz de trazer ordem à desordem e sentido ao sem-sentido da vida, de uma maneira brincalhona, quer dizer, conscientemente sem intenção. A arte é para Oswald de Andrade, segundo Flusser, o jogo da vida que traz ordem e assim tem uma dimensão ética, porque isto significa empenho contínuo. Entre a ordem estabelecida do jogo e a rejeição dessas ordens surgiria, como a arte, a estrutura da vida humana.

Man kann das individuelle Leben, und auch die Geschichte der Menschheit, in seinem spielerischen Wesen verstehen, wenn man das Modell der Künste als Spannungsfeld zwischen Dogma und Revolution heranbringt. Dann stellt sich nämlich heraus, daß das Leben des einzelnen (und das der Gesellschaft) nicht etwa darin besteht, Spiele zu

33 De Andrade 1990b. Esta tese de livre docencia foi apresentada por Oswald de Andrade em 1950, como candidatura a uma cátedra na Universidade de São Paulo. A tese foi recusada. 
stiften, um in ihnen zu siegen, sondern Spiele zu stiften, um sie wieder zu stürzen und neue zu stiften. (Flusser 1970: 134) 34 $^{34}$

Chama a atenção, no entanto que Flusser, na sua discussão do estudo A crise da filosofia messiânica de Oswald de Andrade, escolhe, acima de tudo, este aspecto do jogo que mais o interessa. Aguça as suas observações nesse sentido, sem mencionar a hipótese unida da dinâmica 'antropofágica', respectivamente do desprendimento iniciado na era messiânica-paternalista para a era antropófaga-matriarcal (i. e. colletivo-social). Uma hipótese, que Oswald de Andrade descreveu detalhadamente ${ }^{35}$. No texto de Flusser, pela concentração no 'jogo' existencial, a relação entre a 'antropofagia' inicial de Oswald e seu texto filosófico posterior não está evidente.

No pensamento oswaldiano, Flusser vê antes uma forma interessante do existencialismo, uma "fruchtbare Alternative für [!] das absurde Leben eines Camus, die Alternative des bewußt absichtslosen künstlerischen Schaffens" ("alternativa fértil para [!] a vida absurda de um Camus, a alternativa da criação artística conscientemente e sem intenção")(Flusser 1970: 135). Conveniente a sua própra atitude de 'engajamento' em face ao absurdo da vida.

Por fim sim, recorre à metáfora antropofágica, quando esccreve sobre o efeito do pensar de Oswald de Andrade:

\footnotetext{
${ }^{34}$ [Observando o modelo das artes como área de conflito entre dogma e revolução, entende-se a vida individual e também a história da humanidade na sua substância lúdica. Porque então verifica-se, que a vida do indivíduo (a da sociedade) não consiste em providenciar jogos para vencer neles, mas em providenciar jogos, para derrubá-los e providenciar jogos novos.]

${ }^{35}$ Oswald de Andrade, no início de seu texto, coloca os dois sistemas culturais em conflito: "[...] tudo se prende à existência de dois hemisférios culturais que dividiram a história em Matriarcado e Patriarcado. Quele é o mundo do homem primitivo. Este, o da civilização. Aquele produziu cultura antropofágica, este, uma cultura messiânica."(de Andrade, 1990b: 102).
}

Brasiliana - Journal for Brazilian Studies. Vol. 2, n.1 (March 2013). ISSN 2245-4373. 
[...] Andrade [ist] ein Denker, ohne den schon heute die brasilianische Philosophie nicht $\mathrm{zu}$ verstehen ist, und mit dem morgen der philosophische Dialog überhaupt zu rechnen haben wird, um ihn einzuverleiben und zu überwinden ${ }^{36}$.

Observando detalhadamente, Flusser prossegue um jogo antropofágico não somente com a sua reavaliação dos conceitos históricos. O artigo está marcado por traços de uma incorporação muito mais profunda, porque evidentemente, Flusser 'devorou' o pensar do filósofo e antropófago Oswald de Andrade, o 'digeriu' e o 'processou' de acordo com as suas próprias necessidades em seu texto. Talvez o próprio Flusser falaria antes de uma 'superação' de Oswald de Andrade, mas no fundo, seu texto é um exemplo de uma contaminação contínua com o pensar de Andrade. $O$ 'pôr entre parêntesis' fenomenologista do conhecimento técnico e profissional que Flusser postulou no início do seu ensaio (Flusser 1994a: 15-16) se torna, no percorrer das suas exposições, mais e mais num modo do jogo da 'incorporação' do conhecimento ex-cêntrico, não-disciplinar.

Desde o ponto de vista de hoje, é exatamente esse metabolismo subliminar que ocorre no ensaio flusseriano sobre o Brasil e que oferece pontos de partida para reflexões nas teorias culturais.

O que primeiro e acima de tudo chama a atenção é a reflexão de Flusser sobre as percepções diferentes do Brasil, e a sua encenação das perspectivas de observação diferentes. Ele consegue, em certa medida, desmascarar 'construções' de idéias européias sobre o Brasil. Consegue fazê-lo contextualizando conceitos supostamente

\footnotetext{
${ }^{36}$ [[...] Andrade [é] um pensador, sem o qual a filosofia hoje seria incompreensível, e com quem o diálogo filosófico de amanhã tem que contar, para devorá-lo (incorporá-lo) e superá-lo] (Ibid. Salientado por S. Klengel). O desenvolvimento no campo das teorias culturais deu razão a Flusser, porque a "antropofagia" atua hoje como um impulso para as teorias de hibridação cultural. Hibridação pensada mais como um processo e menos, como superação como expressa Flusser, com base em um antigo conceito da história.
} 
neutros e científicos. Pode-se ler a intuição que Flusser possui por meio do seu trabalho 'antropofágico' com os conceitos europeus. Nota-se sua percepção sobre a assimetria nas estruturas das percepções entre centro e periferia e sua sensibilidade para a 'diferença colonial', embora sua própria opinião sobre o fosso entre o mundo 'desenvolvido' e 'subdesenvolvido' esteja fortemente marcado pelo conceito de história como história do progresso e da teoria da dependência, com seu credo no sistema histórico-econômico. Faz parte desse contexto também o intersse de Flusser por todas as formas de hibridação cultural, mesmo que Flusser associe 'mistura cultural' à demanda pelo novo, em um sentido enfático. Não deixa de chamar a atenção a expressão de uma repulsa ante tudo que é 'Kitsch'. O qual leva a um paradoxo, já que muitos fenômenos da hibridização, na percepção de Flusser, têm que ser desvalorizados como imitações não-criativas.

Enfim, uma das razões pelas quais o ensaio de Flusser sobre o Brasil parece tão interessante é, porque as suas próprias atividades antropofágicas estão dirigidas ao mundo do saber brasileiro, que foi devorado por ele.

Só uma reconstrução abrangente das suas bibliófagas 'refeições brasileiras' revelará o seu lugar como intelectual brasileiro. Ao mesmo tempo, revelará um jogo tenso de interações trans-atlânticas sobre a mediação e 'tradução' de idéias e conceitos, que não tem nada a ver com a idéia da 'defasagem' ou o atraso da constituição do conhecimento.

\section{Literatura}

Andrade, Oswald de (1990a): „Anthropophagisches Manifest“ [1928]. Trad. por Maralde Meyer-Minnemann com colaboração de Berthold Zilly. Em: Lettre International 11, 2, 4041. 
. (1990b): “A crise da filosofia messiânica" [1950]. Em: Id.: Obras Completas. Vol. 6: A utopia antropofágica. São Paulo: Globo, 101-155.

Baitello Junior, Norval (2007): Flussers Völlerei. Wie der nulldimensionale Raum die anderen Dimensionen verschlingen kann. Über die Verschlingung der Natur, die Treppe der Abstraktion, die Auflösung des Willens und die Weiblichkeit. Colônia: Walther König/Vilém_Flusser_Archiv.

Bense, Max (1965a): Brasilianische Intelligenz. Eine cartesianische Reflexion. Wiesbaden: Limes.

. (1965b): „Konkrete Poesie“. Em: Sprache im technischen Zeitalter 15 (No. monográfico: Texttheorie und Konkrete Dichtung), 1236-1244.

Campos, Haroldo de (1966): Versuchsbuch. Galaxien. Trad. por Vilém Flusser e Anatol Rosenfeld. Stuttgart (Coleção Rot, 25).

· (1990): „Über kannibalische Vernunft. Europa unter dem Zeichen der Einverleibung“ [1981]. Trad. por Maralde Meyer-Minnemann. Em: Lettre International 11, 2, 39-45.

Dantas Mota, Lourenço (ed.) (2001): Introdução ao Brasil. Um banquete no trópico. Vol. 1, $3^{\text {a }}$ ed., São Paulo: Editora Senac.

Dewulf, Jeroen (1999): Hugo Loetscher und die ,portugiesischsprachige Welt'. Werdegang eines literarischen Mulatten. Berna u. a. : Lang.

Flusser, Vilém (1967): „Há Filosofia no Brasil? Demonstração em três pensadores expressivos“. Trad. por Irineu Strenger. Em: Revista Brasileira de Filosofia 17, 65, 3-9. . (1970): „Brasilianische Philosophie“. Em: Staden-Jahrbuch. Beiträge zur Brasilkunde und zum brasilianisch-deutschen Kultur- und Wirtschaftsaustausch 16, 131-141. . (1994): Brasilien oder die Suche nach dem neuen Menschen. Für eine Phänomenologie der Unterentwicklung. Ed. de Stefan Bollmann e Edith Flusser. Bollmann: Mannheim. 
. (1994a): „Brasilien oder Die Suche nach dem neuen Menschen. Versuch über den

Brasilianer". Em: Id.: Brasilien oder die Suche nach dem neuen Menschen. Für eine Phänomenologie der Unterentwicklung. Ed. De Stefan Bollmann e Edith Flusser. Bollmann: Mannheim, 7-166.

. (1994b): „Wie philosophiert man in Brasilien? Dargestellt an drei exemplarischen Denkern“ [Frankfurter Allgemeine Zeitung, 03.01.1967]. Em: Id.: Brasilien oder die Suche nach dem neuen Menschen. Für eine Phänomenologie der Unterentwicklung. Ed. de Stefan Bollmann e Edith Flusser. Bollmann: Mannheim, 229-236.

. (1998): Fenomenologia do brasileiro. Em Busca de um Novo Homem. Ed. de Gustavo Bernardo Krause. Rio de Janeiro: Eduerj.

- (1999): „Heimat und Heimatlosigkeit“ (palestra, August 1985). Gravação original, não abreviado. CD Vilém Flusser: „Heimat und Heimatlosigkeit“. Colônia: c+p supposé.

Freyre, Gilberto (1965): Herrenhaus und Sklavenhütte. Ein Bild der brasilianischen Gesellschaft. Ed. de Ludwig Graf von Schönfeldt. Colônia/Berlim: Kiepenheuer \& Witsch. „Há Filosofia no Brasil? Diálogo de Nelson Nogueira Saldanha e Vilém Flusser“ (1967). Em: Revista Brasileira de Filosofía 17, 67, 300-304.

Jackson, David (1996): „Literary Criticism in Brazil“. Em: González Echevarría, Roberto/Pupo-Walker, Enrique (Ed.): Cambridge History of Latin American Literature. Vol. 3, Nova York u. a.: Cambridge Univ. Press, 329-343.

Klengel, Susanne (1996): „Der Atlantik im Zeitalter von Gilberto Freyre, Fernand Braudel und Carlos Fuentes: Begegnungen - Lektüren - Kommentare“. Em: Neue Romania 17, 55-80.

Mignolo, Walter (2000): Local Histories / Global Designs. Coloniality, Subaltern Knowledges, and Border Thinking. Princeton: Princeton Univ. Press.

Brasiliana - Journal for Brazilian Studies. Vol. 2, n.1 (March 2013). ISSN 2245-4373. 
Paim, Antonio (1984): História das idéias filosóficas no Brasil. 3a ed, 3. impressão., São Paulo: Ed. Convívio/Instituto Nacional do Livro/Fundação Nacional Pró-Memória (1a ed. 1967).

Rodrigues, José Honório $(\mathrm{s} \backslash \mathrm{d})$ : „As tendências da historiografia brasileira e as necesidades da pesquisa“. Em: As Ciências Sociais na América Latina. Ed. do Centro Latinoamericano de Pesquisas em Ciências Sociais. São Paulo: Difusão Europeia do Livro, 77-102.

Rosa, João Guimarães (1964): Grande Sertão. Trad. por Curt Meyer-Clason. Colônia/Berlim: Kiepenheuer \& Witsch.

Saldanha, Nelson (1985): A Escola do Recife. 2a ed. 2. impressão., São Paulo: Convívio/Instituto Nacional do Livro.

Sampaio, Prado (1967): „Os nossos filósofos“ [1907]. Em: Revista Brasileira de Filosofia 17, $67,316-327$.

Schumm, Petra (Ed.) (1998): Barrocos y Modernos. Nuevos caminos en la investigación del Barroco iberoamericano. Frankfurt/M./Madrid: Vervuert/Iberoamericana.

Tradução: Susanne Gather Revisão: Dr. Vinicius Mariano de Carvalho e Prof. Dr. Susanne Klengel 